\title{
Genetic counselling and testing for inherited gene mutations in newly diagnosed patients with breast cancer: a review of the existing literature and a proposed research agenda
}

\author{
Bettina Meiser ${ }^{1,2}$, Kathy Tucker ${ }^{1}$, Michael Friedlander ${ }^{1,2}$, Kristine Barlow-Stewart ${ }^{3}$, \\ Elizabeth Lobb ${ }^{4,5,6}$, Christobel Saunders ${ }^{7}$ and Gillian Mitchell ${ }^{8}$
}

\author{
1'Department of Medical Oncology, Prince of Wales Hospital, Randwick, NSW 2031, Australia \\ 2Prince of Wales Clinical School, University of New South Wales, Randwick, NSW 2031, Australia \\ ${ }^{3}$ Centre for Genetics Education, Royal North Shore Hospital, St Leonards, NSW 2065, Australia \\ ${ }^{4}$ Centre for Medical Psychology and Evidence-based Decision-making, University of Sydney, University of Sydney, NSW 2006, Australia \\ ${ }^{5}$ WA Centre for Cancer \& Palliative Care, Curtin University of Technology, Bentley, WA 6102, Australia \\ 6WA Centre for Cancer \& Palliative Care, Edith Cowan University, Joondalup, WA 6027, Australia \\ ${ }^{7}$ School of Surgery, University of Western Australia, 35 Stirling Highway, Nedlands, WA 6009, Australia \\ 8 Jack Brockhoff Familial Cancer Centre, Peter MacCallum Cancer Centre, East Melbourne, VIC 3002, Australia
}

Corresponding author: Bettina Meiser, b.meiser@unsw.edu.au

Published: 28 November 2008

This article is online at http://breast-cancer-research.com/content/10/6/216

(c) 2008 BioMed Central Ltd
Breast Cancer Research 2008, 10:216 (doi:10.1186/bcr2194)

screening of the $B R C A$ genes due to the rarity of the other syndromes and the paucity of associated evidence in terms of the implications for breast cancer management.) Most women with breast cancer and a relevant family history are referred following completion of surgery and adjuvant chemotherapy and/or radiotherapy. The resulting genetic information may provide the basis for advice regarding their personal future risk management and for risk clarification for their unaffected blood relatives [1,2]. Currently, there is usually little urgency for genetic counselling and testing as the outcomes have generally not altered or directly influenced the initial cancer management in an individual patient [3].

However, there is growing evidence that knowledge of $B R C A$ mutation status or a high likelihood of a hereditary cancer syndrome may influence specific treatment recommendations [4-6]. At this time, the major contribution of a confirmed $B R C A$ mutation status is to the decision between selection of a breast conserving approach or a therapeutic mastectomy with or without a contralateral risk-reducing mastectomy. In the future it may also direct the selection of adjuvant chemotherapy if agents targeted to BRCA mutation status, such as the poly (ADP-ribose) polymerase (PARP) inhibitors, prove effective in clinical trials. Targeted genetic counselling and testing is now increasingly being offered and used for surgical management decisions because of the very good survival from early breast cancer [7] and the technical advances in genetic testing, which mean genetic test results

$\mathrm{ER}=$ oestrogen receptor; $\mathrm{PARP}=$ poly (ADP-ribose) polymerase; $\mathrm{RRSO}=$ risk-reducing prophylactic salpingo-oophorectomy. 
can be available within a few weeks. As the survival from early breast cancer continues to improve, the importance of considering the risk of developing a new primary breast cancer increases and may impact on the surgical management of the current cancer. Consequently, it seems likely that more women will be offered genetic counselling and testing for inherited $B R C A$ mutations shortly after diagnosis and the results used to determine appropriate cancer therapy [3], primarily as it relates to the prevention of future cancer risks. Hereafter, genetic counselling and testing offered shortly after diagnosis while treatment options are being considered will be referred to as 'treatment-focused genetic counselling and testing'. Such an intervention, with all its familial considerations, occurs at a vulnerable time when the woman is coming to terms with her diagnosis and making decisions about treatment options.

Linking the results of genetic counselling and testing to subsequent patient management is likely to impact on familial cancer services by increasing the number of patients and their unaffected relatives referred for genetic counselling and testing and the need for patients to be seen soon after referral in already under-resourced services. The subsequent increase in the number of mutation-positive families and the need to provide additional psychosocial support to these women and their families will impact even further on services already struggling under personnel and funding constraints [8]. For example, in the UK almost 2,200 women under the age of 40 years (5\% of all new female breast cancer cases) are diagnosed with breast cancer each year [9], and there is evidence that a significant proportion of these will have a mutation in either of the BRCA1 or BRCA2 genes. Inclusion of treatment-focused genetic counselling and testing will also impact on the current clinical pathways within the associated breast oncology units. Although the familial cancer clinic is recognised as part of the multidisciplinary team, its current role is more consultative in nature and adoption of treatment-focused genetic counselling and testing will mean a change to the current management protocols and established work practices.

This paper highlights the evolving role of treatment-focused genetic counselling and testing and its application to daily clinical practice and patient management. There is a growing need to develop and trial cost-effective clinical pathways for genetic counselling and testing that are responsive to the timeframes demanded in acute cancer management. There will also be a need to address and target resource allocation to best meet the broader health service needs for individual patients and their families that will arise as a direct consequence of referral for genetic counselling to help with treatment decision-making $[8,10]$. Clearly, innovative new service models need to be developed for the delivery of treatment-focused genetic counselling and testing to patients in already stretched busy clinics. In particular, the potential roles of health professionals who are already part of the patient's treatment team (including breast surgeons, gynae- cological oncologists, radiation and medical oncologists) in the delivery of treatment-focused genetic counselling and testing require careful consideration.

This paper reviews: the current literature regarding the potential benefits of using germline $B R C A$ mutation status to tailor the management of newly diagnosed patients with breast cancer; the criteria used to identify patients most likely to carry mutations in the BRCA genes; and the factors that influence women's decision-making and attitudes regarding treatment-focused genetic testing as well as its potential impact on psychological adjustment and breast surgery choices. Although the focus of the literature to date has been on genetic testing for $B R C A$ mutations, it is important to emphasise that it is not simply genetic testing for $B R C A$ mutations that is important for directing cancer treatment. Rather, it is treatment-focused genetic counselling, which focuses on the potential impact of the personal and family history of cancer on future cancer risks and may include genetic testing for mutations in BRCA or other breast cancer predisposition genes, that provides the hereditary cancer risk assessment necessary to inform therapeutic choices.

The aim of this paper is to raise awareness of the increasing role of genetic counselling and testing in the therapeutic arena and to delineate and highlight the associated research priorities. The article provides the basis for the formulation of guidelines as they relate to the use of genetic counselling and testing to inform treatment in certain newly diagnosed patients with breast cancer.

\section{Literature search strategy}

To provide guidance on the criteria that may be used to select women for treatment-focused genetic testing, we undertook a systematic literature search. Studies were included in the review if they met the following criteria: they assessed mutation frequency in women with early onset breast cancer who were unselected for family history; they were published in a peer-review journal; they were published between January 1997 and October 2008; and they were published in the English language. Both studies that recruited through hospitals as well as population-based studies were included. Studies that included women of all ages (even if they reported data on young women separately) were excluded. The CDROM databases PubMed (which includes MEDLINE), Psychlnfo, CINAHL, and EMBASE were searched, using the following key words individually and in combination: 'breast cancer', 'early onset', 'young women', 'prevalence', 'mutation frequency', 'BRCA1', 'BRCA2'. Searches were conducted for key authors who published in this field. The reference lists accompanying all publications identified were examined.

\section{Literature research process and results}

Articles that met the inclusion criteria were evaluated, and data from these articles were extracted (BM). The included articles were checked by a second reviewer to determine if 
they met the inclusion criteria (KT). The literature search identified 309 references as potentially relevant. After reviewing these, 22 references were selected for detailed review (Table 1).

\section{Role of BRCA mutation status in guiding clinical management of patients newly diagnosed with breast cancer Genetic testing and decision-making about breast cancer surgery}

Breast conserving surgery (followed by radiotherapy) is the treatment of choice for many women diagnosed with an early breast cancer. Most women with early breast cancer are cured from their disease [7], and evidence suggests there is no difference in mortality at 10 years between $B R C A$ mutation carriers and non-carriers [11]. However, in women who carry a $B R C A$ mutation, the risk of a recurrence or a new primary in the ipsilateral breast at 10 years is estimated to be as high as $20 \%$ to $50 \%$ [12]. The risk at 10 years for a contralateral second primary cancer is approximately $30 \%$ and is modestly greater for women diagnosed before age 50 years $[13,14]$. There is good evidence that contralateral risk-reducing mastectomy decreases the risk of breast cancer by up to $95 \%$ [15-19]. Therefore, as survival from early breast cancer continues to improve, consideration of the risk of developing a new primary breast cancer becomes more important if it impacts on the surgical management of the current cancer.

While the discussion so far has focused on known $B R C A$ mutation carriers, it is important to emphasise that simply relying on the presence or absence of a $B R C A$ mutation after a genetic test is an inadequate assessment of a woman's likely future cancer risks. A woman with breast cancer in whom a $B R C A$ mutation has not been detected with current techniques may still have a significant risk of developing a new primary cancer depending on her associated family history, which, in turn, could still influence her decision regarding breast conserving surgery. Genetic counselling is an essential component of the genetic risk assessment in order to interpret the implications of a genetic test result, particularly if no mutation can be identified - an 'uninformative' result. The clinical implications of an uninformative result depend on whether or not a woman has a relevant family history of breast and/or ovarian cancer. Specifically, in a woman with a strong family history of breast and/or ovarian cancer, there is no convincing evidence that in the absence of a detectable mutation there is a substantial reduction in the chance of ipsilateral and/or contralateral breast cancer. There is some evidence that the risk of a second primary remains elevated in BRCA1 and BRCA2 mutation negative families, especially if the breast cancer was diagnosed early [20]. Thus, women with a relevant family history of breast and/or ovarian cancer who receive uninformative results may still reasonably consider risk-reducing surgery on the basis of their strong family history alone. It is important that the information is discussed with genetic specialists to ensure correct interpretation of results, but also that these specialists understand that absence of a detectable mutation does not preclude a substantial risk of a further primary.

In other circumstances, specific personal and family features may mean that an uninformative test may support an assessment that it is less likely there is a hereditary syndrome, thus reducing estimates of risks for a new ipsilateral or contralateral breast cancer. In this instance, the woman can make an informed decision and reasonably elect breast conservation.

It is possible that a significant proportion of women found to have a deleterious mutation would opt for bilateral mastectomy if they had access to this information at diagnosis [21-25]. If a woman is identified as a BRCA mutation carrier, the mutation status can be used as a variable in the complex decision-making process regarding the use of radiotherapy and the type of surgery. The option of combining definitive and risk-reducing surgery as a unilateral or bilateral mastectomy after adjuvant therapy is completed avoids the need for additional surgery if a woman would have elected risk-reducing surgery at a later date following delayed genetic counselling with or without genetic testing [26]. Furthermore, radiation treatment, which may negatively impact on the cosmetic outcome of breast reconstructive surgery, may be able to be avoided.

The discussion so far has focused on the relative roles of breast conservation versus mastectomy, so it could be argued that treatment-focused genetic counselling and testing need not be considered at this vulnerable time if women do not want to consider a mastectomy. However, we would argue that although a woman may not want to consider a mastectomy as her first reaction to a new cancer diagnosis, if she has a suspicious family history and does not have the opportunity for a full consultation about the possible associated cancer risks, she risks not being fully informed about the pros and cons for all the treatment choices available.

\section{Decision-making about risk-reducing salpingo- oophorectomy}

Women newly diagnosed with breast cancer with a $B R C A$ mutation may also consider a risk-reducing salpingo-oophorectomy (RRSO) to reduce their significant associated future ovarian cancer risk [27]. RRSO has been shown to reduce the risk of ovarian cancer by between $85 \%$ [28] and 95\% [29]. It also reduces the risk of subsequent breast cancer by up to $50 \%$ in BRCA1 and BRCA2 mutation carriers [28-31], with risk reduction being greatest for premenopausal women.

Although the cancer prevention considerations are important, the main indication for considering such surgery around the time of cancer diagnosis is because an oophorectomy is also an effective adjuvant treatment for oestrogen-receptor (ER) positive premenopausal breast cancer. Furthermore, RRSO will also permit the use of adjuvant aromatase inhibitors, 


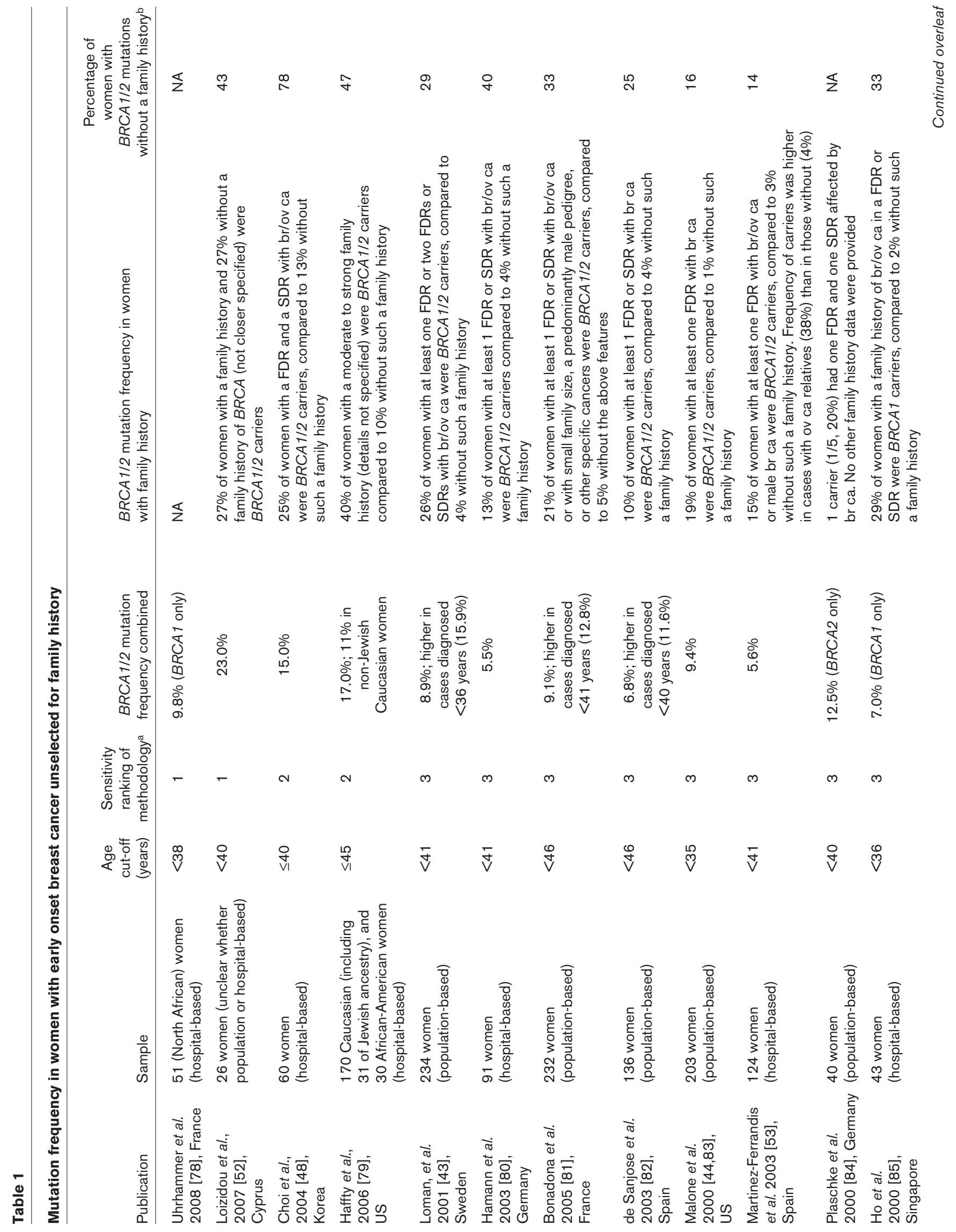




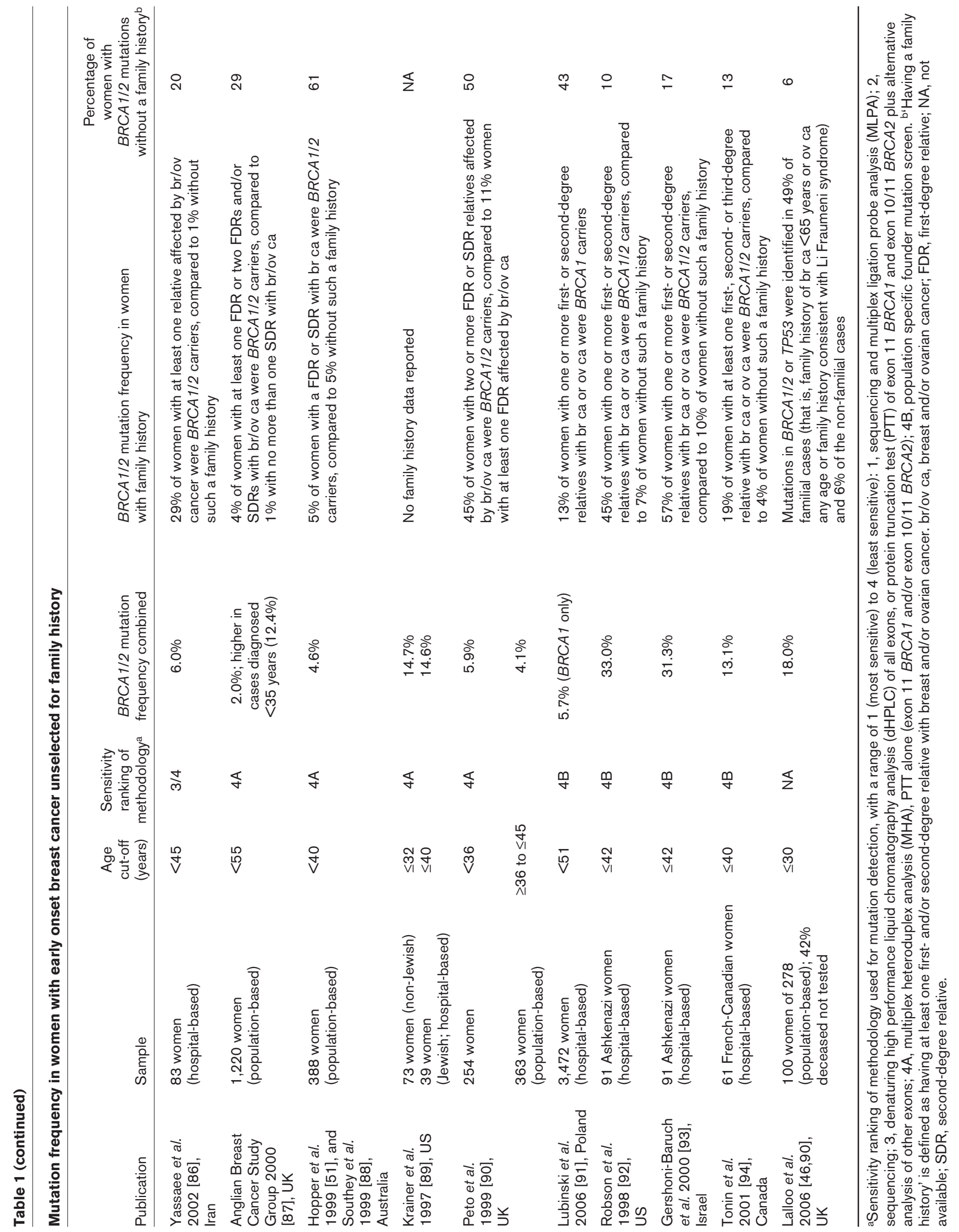


which are superior to tamoxifen but are only effective in postmenopausal women [32,33]

\section{Potentially increased scope of the future uses of treatment-focused genetic counselling and testing}

There are emerging data that indicate that complete cellular loss of BRCA1 or BRCA2 function in BRCA-associated cancers confers increased resistance to agents such as taxanes [34], and that these tumours are more sensitive to DNA-damaging agents such as platinum agents [35]. It is reasonable, therefore, to speculate that the known or likely $B R C A$ mutation status of a woman could influence systemic therapy decisions and choice of chemotherapy once we have more definitive data from randomised trials. Moreover, further refining of pathological techniques may allow treatment targeted at aberrant molecular pathways of the tumour, which may be related to both somatic and germline BRCA mutations as well as other predictive markers. There is evidence that BRCA1-associated breast cancers are more aggressive $[36,37]$, and that adjuvant chemotherapy should be considered in the majority of mutation positive women, even those with small, node negative breast cancers.

As well as improvements in the understanding of the relative efficacies of conventional chemotherapy agents in the adjuvant treatment of BRCA1 or BRCA2 mutation carriers, novel agents such as PARP inhibitors have been developed that exploit the effect of a mutated gene in the associated cancers. The BRCA1 and BRCA2 genes are important for DNA double-strand break repair by homologous recombination. PARP is an enzyme involved in base excision repair, a key pathway in the repair of DNA single-strand breaks [38]. The inhibition of PARP results in the development of DNA double-strand breaks that are normally repaired through the homologous recombination pathway mediated by BRCA1 and BRCA2. The BRCA1 or BRCA2 dysfunction occurring in cancers arising in $B R C A 1$ or BRCA2 germline mutation carriers sensitises tumour cells to the inhibition of PARP enzymatic activity, resulting in chromosomal instability, cell cycle arrest and apoptosis, as these cells have no functioning copy of the BRCA genes. The other body cells are relatively insensitive to the effects of PARP inhibition as these cells still retain a functioning $B R C A 1$ or BRCA2 gene. Consequently, the use of PARP inhibitors in BRCA-associated cancer has the potential for a wide therapeutic index between the effects of PARP inhibition on tumour and normal body cells [39].

Clinical trials using PARP inhibitors are underway in BRCAassociated cancers [40]. If successful, and if they progress into the adjuvant arena, the use of PARP inhibitor agents will increase the need to ascertain a patient's BRCA mutation status around the time of cancer diagnosis. The results of phase 1 and 2 studies show that PARP inhibitors are very active agents [41], and it is likely that they will be investigated in the adjuvant setting for women with early stage breast cancer within the next few years.

\section{Complexity of decision-making about treatment- focused genetic counselling and testing}

There is a growing awareness of the potential benefits of understanding a woman's likely hereditary cancer risk status for the consideration of simultaneous therapeutic and contralateral risk-reducing mastectomy, better tailoring of conventional adjuvant therapies and the testing of novel agents in the adjuvant setting. There is a small window of opportunity to establish the optimal ways in which to offer treatmentfocused genetic counselling and testing and to develop appropriate associated clinical pathways, in advance of a more widespread clinical demand.

The development of educational resources that support women considering genetic counselling and testing to make informed decisions as well as facilitating discussions between women and their health professionals is also critical. These resources will need to provide information for women to consider the potential advantages and disadvantages of this process. These include the added stress of undergoing genetic testing for a hereditary predisposition around the time of a breast cancer diagnosis; the implications of uninformative genetic test results; the possibility of delaying surgery for a short time while waiting for genetic testing results if there is no planned delay in definitive surgery or radiotherapy due to neoadjuvant or adjuvant chemotherapy; and the implications of this information for the wider family.

Raising the issue about the hereditary aspects of breast cancer at the time of diagnosis involves more than considering the usual pros and cons of genetic testing and, if a mutation is found, discussing the role of mastectomy as a risk-reducing strategy at some time in the future. It adds another layer of complexity to the decisions around cancer treatment when providing women with the opportunity to consider the wider issues that may affect their future survival and possible disease course rather than using the tumour staging and characteristics alone. There are a variety of management options, and this is complex information to convey at a vulnerable time, so this will require multidisciplinary input from breast surgeons, plastic surgeons, medical and radiation oncologists as well as other health professionals involved in the care of women with breast cancer outside traditional genetic counselling services. Involvement of genetic specialists in the multidisciplinary team will ensure that these issues are brought up, but also that patients are not disadvantaged by ill informed application of these genetic tests. As genetic testing becomes faster and cheaper, some clinicians might believe that testing results indicate a clear set of treatment options. It is, however, essential that the decisions that arise as a result of genetic testing be considered within the context of the priorities of treating the current cancer. Integration of a new model of genetic counselling and testing to help direct therapy may also challenge assumptions that women who are coping with a recent diagnosis of breast cancer, and are already making 
multiple decisions about their treatment are not interested in, or able to cope with, additional information about their genetic risk.

\section{Targeting of treatment-focused genetic testing to certain patients with newly diagnosed breast cancer}

The current costs of genetic testing and a climate of cost constraints mean that treatment-focused genetic testing will need to be targeted to the women who have a reasonable chance of being mutation carriers. How to select women appropriately is problematic. The traditional approach of only offering genetic testing to women in a potentially high-risk group based on their family history alone is being challenged as there is accumulating evidence that many women with mutations in BRCA1 or BRCA2 genes do not have a classic family history (Table 1) $[42,43]$. Other indicators are now also being considered to provide a basis for the selection for testing, such as phenotypic pathological characteristics of the tumour tissue (for example, basal-like phenotype). Treatment-focused genetic testing will be no different and case selection should include consideration of the classic features, including a strong family history of breast and/or ovarian cancer, younger age at breast cancer diagnosis, presence of bilateral breast cancer, membership in an ethnic group with a high incidence of founder mutations (for example, Ashkenazi Jewish background), in addition to the tumour tissue characteristics. The evidence available to support the adoption of such selection criteria are described briefly below.

\section{Women with a strong family history of breast and/or ovarian cancer}

There is strong evidence that the frequency of mutations in $B R C A 1$ or BRCA2 genes is increased in women with a strong family history of breast and/or ovarian cancer involving multiple generations of affected blood relatives and/or those with a specific ethnicity or from certain geographical locations that are associated with known founder mutations. For example, Malone and colleagues [44] provide a summary of the literature and report that in women with extensive family histories, estimates of mutation frequency range from $20 \%$ to $50 \%$. There is a consensus that women with strong family histories of breast and/or ovarian cancer should be offered genetic counselling and testing for mutations in the two BRCA genes (for example, National Breast Cancer Centre [45] and American Society of Clinical Oncology $[1,46])$.

However, it is also clear that many mutation carriers will be missed if the presence of a strong family history of breast cancer and/or ovarian cancer is used as the sole criterion to offer genetic testing. Table 1 provides a summary of published studies on women with early onset breast cancer who have had genetic testing for BRCA1 and BRCA2 mutations; it shows that the proportion of women with a BRCA1 or BRCA2 mutation with no family history of breast/ovarian cancer ranges from $6 \%$ [47] to $78 \%$ [48]. The lack of a family history of breast and/or ovarian cancer can arise because of a small family size, few female relatives of an age to have developed cancer, patrilineal inheritance, low cancer penetrance and non-disclosure of relevant family cancer diagnoses due to geographic or social distance between relatives $[42,49]$.

\section{Women with early onset breast cancer}

Table 1 also shows that the proportion of women found to have mutations in BRCA1 or BRCA2 genes varies considerably between studies, ranging from $2.0 \%$ to $33.0 \%$. This variability is likely to be the result of differing populations, age selection criteria and mutation detection methods utilised. Studies vary in the extent to which they include women from ethnic backgrounds characterised by the presence of founder mutations, which will have specific population frequencies not applicable to a wider outbred population. The age selection criteria chosen for different studies also vary between under 31 to under 55 years. Finally, the diagnostic sensitivity of the methods used for the detection of BRCA1 and BRCA2 mutations varies [50]. Accordingly, in Table 1 the studies are ranked for sensitivity of the mutation detection method. Sensitivity estimates are based on published data only and do not take into account the operator dependence of these methodologies.

Extracting the data for women aged under 40 years from the studies in Table 1 gives a BRCA mutation detection rate of between $4.9 \%$ [51] and $23.0 \%$ [52]. A prior probability of mutation detection exceeding $10 \%$ [1] is generally considered sufficiently high to justify genetic testing for $B R C A$ mutations through many public genetics clinics. It should be noted though that this threshold is not based on health economic analyses, and the cut-off to be used will depend on local availability of resources and ethnic mix.

Women with early onset breast cancer and a family history of breast/ovarian cancer

Several studies found that women with early onset breast cancer who have at least one first-degree or one first- and one second-degree relative with breast or ovarian cancer have higher mutation frequencies (Table 1) and may be suitable candidates for treatment-focused genetic testing. For example, Loman and colleagues [43] found that in women aged 40 years and under, 39\% of women with this degree of family history carried mutations in BRCA1 or BRCA2. Similarly, Martinez-Ferrandis and colleagues [53] found that even a moderate family history was a good predictor of BRCA1 or BRCA2 mutation status; $15.4 \%$ of women with at least one first-degree relative with breast or ovarian cancer or one case of male breast cancer were BRCA1 or BRCA2 mutation carriers. Lalloo and colleagues [47] found an even higher rate of mutation carriers in women under the age of 31 years with a first- or second-degree relative with breast and/or ovarian cancer (44\%), compared to those without such a family history. 
Women with early onset bilateral breast cancer

Young women with bilateral breast cancer have a higher chance of a BRCA mutation than their counterparts with unilateral disease. For example, Loman and colleagues [43] found that $33 \%$ of women aged 40 and under with bilateral cancer were $B R C A 1$ or BRCA2 mutation carriers.

Women whose tumours have certain histological characteristics Tumour pathology is increasingly useful in case selection for $B R C A$ genetic testing [42]. Specifically, it has been shown that BRCA1-associated tumours have a distinct immunohistochemical profile associated with the basal-like phenotype [42].

Lakhani and colleagues [54] showed that information on age at diagnosis, high histological grade and an ER negative receptor status provides a powerful predictor of $B R C A 1$ mutation status. Specifically, in women who were aged between 30 and 34 years at diagnosis, the probability of presence of a BRCA1 mutation increased from $5 \%$ for women with all histology, to $27 \%$ for women with ER negative and grade 3 histology. The data reported by Lakhani and colleagues suggest that women aged under 35 years with ER negative breast cancers, regardless of grade, have BRCA1 mutation frequencies much greater than 10\%. Similarly, Atchley and colleagues [55] found that $34 \%$ and $8 \%$ of women diagnosed with triple negative breast cancer were BRCA1 and BRCA2 mutation carriers, respectively. However, the true rate of $B R C A 1$ mutations in ER negative or 'triple negative' (ER, progesterone receptor and HER2 negative) breast cancer cases is unknown, as there have been no studies looking at the BRCA1 and BRCA2 mutation prevalence in a prospectively collected population-based cohort of cases.

Women with early onset breast cancer from populations with BRCA founder mutations

Specific ethnic factors increase the likelihood of a $B R C A 1$ or $B R C A 2$ mutation in women with early onset breast cancer. For example, Abeliovich and colleagues [56] found a frequency of BRCA1 or BRCA2 mutations of $30 \%$ in women of Ashkenazi Jewish background who developed breast cancer under the age of 40 years. Data from Myriad Genetics clinical testing service [57] show a BRCA1 or BRCA2 mutation prevalence of $12 \%$ in women of Ashkenazi Jewish ancestry with breast cancer who are aged less than 50 years and who have no relevant listed family history. By contrast, the BRCA1 or BRCA2 mutation prevalence in women of Ashkenazi Jewish ancestry with breast cancer aged 50 and over with no relevant family history is considerably lower (4\%). Founder mutations have been identified in many populations, including Swedish, Norwegian, Icelandic, Dutch, Eastern European and French Canadian to name but a few.

\section{Selective testing of certain subgroups of women with early breast cancer}

In conclusion, these data suggest some specific features that may guide selection for treatment-focused genetic counselling and testing, which are summarised in Table 2.
Limited data are currently available on whether to use age 40, 45 or even 50 years as a cut-off to define the group of young women from each of the four groups described above for an offer of treatment-focused genetic testing. Hence, a metaanalysis of existing data and/or more research involving larger samples will be required to decide on optimal age cut-offs. Cost considerations are also likely to be a critical factor, and health economic analyses need to be undertaken to provide a basis for decisions on which mutation prevalence thresholds to use for an offer of treatment-focused genetic counselling and testing consistent with local resources.

\section{Previous attempts at integrating treatment- focused genetic testing into clinical practice}

Several groups have demonstrated that genetic counselling and testing of newly diagnosed breast cancer patients can be integrated successfully into clinical practice $[12,26,58,59]$. Published reports of existing treatment-focused genetic testing programs used varying criteria for selecting patients for the offer of such genetic testing. In particular, three used a minimum of a $10 \%$ probability of carrying a BRCA1 or BRCA2 mutation as assessed by risk assessment models such as BRCAPRO or that of Myriad Genetics [12,58] or on the basis of data from published reports [26]. A fourth program utilised a check list with risk factors thought to be predictive of hereditary breast cancer, which incorporated both family history of breast and/or ovarian cancer as well as young age (regardless of family history) and diagnostic features (bilateral, multifocal and/or multicentric breast cancer), again regardless of family history [59].

These programs also differed in terms of which health professional recommended genetic testing; in one study women self-referred, typically following a physician recommendation [26]. In other programs, testing was offered by cancer clinic staff $[12,58]$, or the health professional offering testing was not specified [59].

The timing of the offer of genetic testing was also variable. In one program women were offered testing before definitive surgical treatment, which was defined as either breast conserving surgery with radiation treatment, or unilateral or bilateral mastectomy; women who had undergone a lumpectomy but not yet commenced radiation therapy remained eligible for testing [26]. Similarly, Stolier and colleagues [58] report that testing results became available either during systemic therapy, or radiation therapy was delayed until results were given, while Weitzel and colleagues [12] report that genetic testing took place either immediately following biopsy, after breast conserving surgery or during chemotherapy. These authors report that definitive surgery was not delayed to accommodate genetic testing, but that radiation therapy did not take place where possible until the results from genetic testing had become available $[12,26]$.

It should be noted that timing of genetic testing before initial surgery has also been proposed; in particular, Silva [5] 
Table 2

Features that may guide selection for treatment-focused genetic counselling and testing

Strong family history consistent with dominantly inherited breast/ovarian cancer
Two or more first- or second-degree relatives on one side of the family plus one or more of the following features on the same side of the familya:

\author{
Additional relatives with breast or ovarian cancer \\ Breast cancer diagnosed before the age of 40 years \\ Bilateral breast cancer \\ Breast and ovarian cancer in the same woman \\ Ashkenazi Jewish ancestry \\ Breast cancer in a male relative
}

One or more first- or second-degree relatives with breast cancer at age 45 years or younger plus another first- or second-degree relative on the same side of the family with sarcoma (bone/soft tissue) at age 45 years or younger

Young age of onset ${ }^{\mathrm{b}}$ especially in combination with:

aNational Breast Cancer Centre [96]. bThe age cut-off to be used will depend on local availability of resources and the future cost of mutation detection.

advocates that genetic counselling and testing be offered during the window of time when some patients are having neoadjuvant therapy. Therefore, either neoadjuvant or adjuvant chemotherapy given prior to radiotherapy can give a useful window in which to consider treatment-focused genetic testing before definitive local surgery.

\section{Women's decision-making about, and the psychological and behavioural impact of, treatment-focused genetic testing Psychological impact of standard genetic testing for BRCA1 and/or BRCA2 mutations}

There is an expanding body of literature about the psychological impact of genetic testing in affected women at increased risk for hereditary breast/ovarian cancer who were offered 'standard' genetic testing for BRCA1 and/or BRCA2 mutations, that is, genetic testing offered in the context of genetic counselling following completion of cancer treatment, as opposed to treatment-focused genetic counselling and testing (see Schlich-Bakker and colleagues [60] and Meiser [61] for reviews). This literature indicates that the impact of genetic testing is mediated and amplified by women's former experience of cancer [61]. Women with a previous diagnosis of cancer have been found to be significantly more distressed compared to unaffected women following genetic testing [62] independently of carrier status [63]. Women for whom the gap between being diagnosed with cancer and being genetically tested was less than a year tend to report greater reductions in well-being compared to those for whom the gap was longer $[64,65]$. This may indicate that genetic testing around the time of diagnosis may place additional psychological stressors on women or that women feel frustrated if they realise they might have selected an alternative therapy had they received genetic counselling prior to completion of cancer treatment. These results do not suggest that treatment-focused genetic testing should not occur, but rather that it should be provided in a supportive environment that is responsive to these wider issues.

\section{Impact of treatment-focused genetic testing for BRCA1} and/or BRCA2 mutations on surgery decisions

Limited empirical data have been published that describe women's decision-making about, and the psychological and behavioural impact of, treatment-focused genetic testing in the context of a new diagnosis of breast cancer. In a key US study, Schwartz and colleagues [21,26,66,67] evaluated the impact on surgical decision-making in 194 newly diagnosed breast cancer patients who were offered testing before definitive surgery. In this study, women with a $10 \%$ prior probability of carrying a BRCA1 or BRCA2 mutation were offered genetic testing, and test results were made available within 2 to 3 weeks. Seventy-six percent of the study participants chose to have BRCA1 and/or BRCA2 testing; the decision to undergo testing was associated with physician recommendation and indecision about definitive local treatment [21]. Twenty-one percent of the women who were tested proceeded with definitive local treatment before receiving their tests results; delays in the availability of test results and low levels of anxiety were associated with the decision to proceed with definitive local treatment [21]. Schwartz and colleagues [21] also found that $48 \%$ of women who were found to carry a BRCA1 or BRCA2 mutation 
opted for bilateral mastectomy, compared to $4 \%$ of women who declined genetic testing. These findings indicate that knowledge of a $B R C A 1$ or BRCA2 mutation before definitive surgery significantly increases the number of women opting for bilateral mastectomy for both treatment and risk reduction $[26,66,67]$. They also suggest that the presentation of the information about genetic testing by the treating clinician is an important factor in the final decision to undertake genetic testing.

\section{Impact of contralateral risk-reducing mastectomy on psychosocial outcomes}

The study by Schwartz and colleagues [26] also found that, compared with women who chose breast conservation or unilateral mastectomy, those who chose mastectomy of the affected breast and contralateral risk-reducing mastectomy of the unaffected breast did not report diminished quality of life or decreased distress [67]. These results are consistent with findings from another study of $435 B R C A 1$ or BRCA2 carriers that assessed predictors and outcomes of the decision to undergo contralateral risk-reducing mastectomy and found no impact on distress outcomes of contralateral risk-reducing mastectomy [66]. In this latter study the decision to undergo contralateral risk-reducing mastectomy (in conjunction with mastectomy of the affected breast) following treatment-focused genetic testing was associated with an informative, mutation positive test result, higher cancer-specific distress at baseline and younger age at diagnosis [66]. Similarly, in an international cohort of women, uptake of contralateral mastectomy was found to be associated with younger age [68].

In the study by Schwartz and colleagues [26,66] women opted into the study and received extensive pre- and posttest genetic counselling; the select nature of the sample and the unique resources of the study limit the generalisability of the results to other settings [69]. Although the data reported by Schwartz and colleagues suggest few adverse psychological effects of treatment-focused genetic testing, further controlled studies in a range of different clinical settings are needed to determine definitively the psychological and behavioural impact of treatment-focused genetic testing for $B R C A 1$ and/or BRCA2 mutations.

In another prospective study from The Netherlands, SchlichBakker and colleagues $[60,70,71]$ assessed predictors of the decision to undergo treatment-focused testing and its psychological impact in women with breast cancer who were about to commence adjuvant radiotherapy. The psychological distress levels of 102 women who met referral criteria for genetic counselling and testing were compared to those of 182 women who did not meet such criteria. The authors report that psychological distress levels did not increase after an active approach for genetic counselling and testing $[60,70]$. Of importance in this setting, not having a family history of breast cancer was found to predict long-term distress in the combined group of tested and untested women $[60,70]$. Of note, of the 102 patients who met referral criteria, only $57 \%$ opted to have genetic testing [71]. Sixtyfour percent of the 102 women were happy with the timing of genetic testing, while 13\% would have preferred an earlier, and $19 \%$ a later, approach [71].

\section{Women's attitudes and information needs regarding treatment-focused genetic testing}

A small UK study by Arden-Jones and colleagues [72] explored whether women wanted to be offered information about genetic testing close to the time of diagnosis. Thirteen women, who were ascertained through a family cancer service, were under the age of 40 and were subsequently identified as BRCA1 or BRCA2 mutation carriers, participated in focus groups. The majority of women expressed the view that offering genetic testing around the time of a breast cancer diagnosis might add too much stress at a time when women were confronted with multiple demands on their coping abilities. However, some women supported testing around the time of breast cancer diagnosis if it could alter treatment decisions. All agreed that there was no 'right' time for everyone, with women expressing a preference for being told that the information was available if they wanted it rather than then being offered the test at the time of their cancer diagnosis. However, a broad range of views was observed and indeed some women said they would prefer to be tested immediately following their breast cancer diagnosis.

\section{Health professionals' attitudes toward treatment- focused genetic testing of newly diagnosed women}

The study by Arden-Jones and colleagues [72] also found that health professionals involved in breast cancer care expressed concerns about informational and emotional overload caused by offering genetic testing at the time of a breast cancer diagnosis. Similar views were expressed in a recent study of 34 Australian cancer genetics practitioners that was undertaken to identify problematic or ethically contentious issues in cancer genetics consultations [73]. The latter study also highlights: the rights of women to be fully informed when making treatment decisions; the need to provide emotional support at this vulnerable time; the importance of including the genetic counsellor in the multidisciplinary team and the impact on the delivery of cancer genetic services with increasing demand for testing [73].

\section{Potential future directions for research on the psychosocial implications of treatment-focused genetic testing}

This overview of the psychosocial literature shows that treatment-focused genetic testing for BRCA1 and/or BRCA2 mutations is not associated with adverse psychological and quality of life outcomes. However, these studies included almost exclusively women with a family history that indicated an increased risk for hereditary breast/ovarian cancer, and very little is known about the psychosocial impact of 
treatment-focused genetic testing in women without a family history. This review also shows that very few data are currently available on: the anticipated implications of genetic testing for the patient and other family members; patient preferences in terms of timing of genetic testing information; mode of delivery of information; and preferred format and amount of information. Furthermore, no educational interventions have been developed to supplement expert advice and counselling of women considering treatment-focused genetic testing.

Given current funding constraints, the potential for routine testing in the future of newly diagnosed breast cancer patients also points to a need to develop and evaluate innovative patient education strategies as time-efficient means to supplement expert counselling provided by health professionals. Possible formats of resources include simple information sheets or more complex communication and decision aids. Communication aids may be used to facilitate and structure the discussion between the patient and the health professional and may also be tailored to the particular patient and taken home to be shared with other family members. Decision aids have been shown to improve understanding of the potential benefits and risks of different options and to assist patients to consider the personal importance of these options [74-77].

\section{Conclusion}

There is increasing interest in treatment-focused genetic counselling and testing. This approach is not indicated for women who would not consider mastectomy or oophorectomy for cancer management because of age considerations or personal preference as they would have little to gain from an expedited genetic assessment. Currently, the main utility of a treatment-focused genetic assessment is to direct surgical therapy, but if agents targeted to BRCA-associated tumours move into the adjuvant arena, then the indications for treatment-focused genetic assessment will increase further.

For those women in whom knowledge of a likely hereditary cancer syndrome or mutation status might alter their cancer treatment, we suggest a stepwise approach to their genetic assessment. Specifically, women who have a strong family history or develop breast cancer diagnosed at a young age regardless of family history may benefit from a formal assessment of the likelihood of a hereditary component to their breast cancer. If possible, an analysis of a threegeneration pedigree should be undertaken in conjunction with the woman's breast cancer pathology. With regard to women without a relevant family history of breast and/or ovarian cancer, there will have to be consideration of an age cut-off for testing depending on local circumstances, local ethnicities and mutation prevalence as well as financial considerations, until the cost of genetic testing substantially reduces. If genetic testing proceeds, it is essential that the results be interpreted within the context of the specific family history so that an accurate hereditary risk assessment can be provided to the patient.

The opportunity currently exists to systematically ascertain the important clinical and psychosocial implications of genetic risk determination for hereditary breast cancer in women newly diagnosed with breast cancer, in advance of the inevitable widespread clinical implementation of treatmentfocused genetic testing. Ethical practice requires confidence that information about genetic risk and testing results can be provided without damaging psychological or behavioural consequences, and that the genetic information is correctly interpreted and relayed to the patient by an appropriate multidisciplinary team. Thus, data on the acceptability of treatment-focused genetic testing for germline BRCA1 or BRCA2 mutations and women's associated information and communication needs are required urgently.

\section{Competing interests}

The authors declare that they have no competing interests.

\section{Acknowledgements}

The authors would like to thank the reviewers for their many valuable suggestions. The authors would also like to acknowledge Dr Alison Trainer for her helpful review and suggestions regarding the manuscript, Dr Kaaren Watt's assistance with the extraction of data from previous reports on BRCA1/2 frequencies, and Dr Margie Smith's review of the tables. Bettina Meiser is supported by a Career Development Award from The National Health and Medical Research Council of Australia (ID 350989). Support was also provided by a Strategic Research Partnership Grant from The Cancer Council of New South Wales ID SRP 06-X5.

\section{References}

1. American Society of Clinical Oncology: American Society of Clinical Oncology Policy Statement. J Clin Oncol 2003, 21: 2397-2406.

2. Australian Cancer Network: Guidelines on Familial Aspects of Cancer. Sydney: Australian Cancer Network; 1999.

3. Mitchell G, Ardern-Jones A, Kissin Mchir M, Taylor R, Eeles RA, Mitchell G, Ardern-Jones A, Kissin Mchir M, Taylor R, Eeles RA: A paradox: Urgent BRCA genetic testing. Fam Cancer 2001, 1: 25-29.

4. Rubinstein W: Hereditary breast cancer: pathobiology, clinical translation, and potential for targeted cancer therapeutics. Fam Cancer 2008, 7:83-89.

5. Silva E: Genetic counselling and clinical management of newly diagnosed breast cancer patients at genetic risk for BRCA germline mutations: Perspective of a surgical oncologist. Fam Cancer 2008, 7:91-95.

6. Domcheck S, Weber B: Clinical management of BRCA1 and BRCA2 mutation carriers. Oncogene 2006, 25:5825-5831.

7. Smith C, Kricker A, Armstrong B: Breast cancer mortality trends in Australia: 1921 to 1994. Med J Australia 1998, 168:11-14.

8. Lean C, Bullivant C, Pagnini D, Tracey E, Hepburn A, Sinclair S, Bishop J: Review of cancer genetics services. Asia Pacific $J$ Clin Oncol 2007, 3(Suppl 2):A63.

9. Breast Cancer Incidence by Age; 2005 [http://info.cancerresearchuk.org/cancerstats/types/breast/incidence/]

10. Iredale R, Elwyn G, Edwards A, Gray J: Attitudes of genetic clinicians in Wales to the future development of cancer genetics services. J Eval Clin Pract 2007, 13:86-89.

11. Rennert G, Bisland-Naggan S, Barnett-Griness O, Bar-Joseph N Zhang S, Rennert HS, Narod SA: Clinical outcomes of breast cancer in carriers of BRCA1 and BRCA2 mutations [see comment]. N Engl J Med 2007, 357:115-123.

12. Weitzel JN, McCaffrey SM, Nedelcu R, MacDonald DJ, Blazer KR, Cullinane CA: Effect of genetic cancer risk assessment on sur- 
gical decisions at breast cancer diagnosis. Arch Surg 2003, 138:1323-1328; discussion 1329.

13. Metcalfe K, Lynch HT, Ghadirian P, Tung N, Olivotto I, Warner E, Olopade OI, Eisen A, Weber B, McLennan J, Sun P, Foulkes WD, Narod SA: Contralateral breast cancer in BRCA1 and BRCA2 mutation carriers. J Clin Onco/ 2004, 22:2328-2335.

14. Pierce LJ, Levin AM, Rebbeck TR, Ben-David MA, Friedman E, Solin LJ, Harris EE, Gaffney DK, Haffty BG, Dawson LA, Narod SA, Olivotto IA, Eisen A, Whelan TJ, Olopade OI, Isaacs C, Merajver SD, Wong JS, Garber JE, Weber BL: Ten-year multi-institutional results of breast-conserving surgery and radiotherapy in BRCA1/2-associated stage I/II breast cancer [see comment]. J Clin Oncol 2006, 24:2437-2443.

15. Herrinton $L$, Barlow WE, Yu O, Geiger AM, Elmore JG, Barton MB, Harris EL, Rolnick S, Pardee R, Husson G, Macedo A, Fletcher SW: Efficacy of prophylactic mastectomy in women with unilateral breast cancer: a cancer research network project [see comment]. J Clin Oncol 2005, 23:4275-4286.

16. van Sprundel TC, Schmidt MK, Rookus MA, Brohet $R$, van Asperen CJ, Rutgers EJ, Van't Veer LJ, Tollenaar RA: Risk reduction of contralateral breast cancer and survival after contralateral prophylactic mastectomy in BRCA1 or BRCA2 mutation carriers. Br J Cancer 2005, 93:287-292.

17. McDonnell SK, Schaid DJ, Myers JL, Grant CS, Donohue JH, Woods JE, Frost MH, Johnson JL, Sitta DL, Slezak JM, Crotty TB, Jenkins RB, Sellers TA, Hartmann LC: Efficacy of contralateral prophylactic mastectomy in women with a personal and family history of breast cancer. J Clin Oncol 2001, 19:39383943.

18. Heemskerk-Gerritsen BA, Brekelmans CT, Menke-Pluymers MB, van Geel AN, Tilanus-Linthorst MM, Bartels CC, Tan M, MeijersHeijboer HE, Klijn JG, Seynaeve C: Prophylactic mastectomy in $B R C A 1 / 2$ mutation carriers and women at risk of hereditary breast cancer: long-term experiences at the Rotterdam Family Cancer Clinic [see comment]. Ann Surg Oncol 2007, 14:33353344.

19. Goldflam K, Hunt KK, Gershenwald JE, Singletary SE, Mirza N, Kuerer HM, Babiera GV, Ames FC, Ross MI, Feig BW, Sahin AA, Arun B, Meric-Bernstam F: Contralateral prophylactic mastectomy. Predictors of significant histologic findings. Cancer 2004, 101:1977-1986.

20. Loman N, Bladstrom A, Johannsson O, Borg A, Olsson H: Cancer incidence in relatives of a population-based set of cases of early-onset breast cancer with a known BRCA1 and BRCA2 mutation status. Breast Cancer Res 2003, 5:R175-R186.

21. Schwartz MD, Lerman $C$, Brogan $B$, Peshkin $B N$, Isaacs $C$, DeMarco $\mathrm{T}$, Halbert $\mathrm{CH}$, Pennanen M, Finch C: Utilization of $B R C A 1 / B R C A 2$ mutation testing in newly diagnosed breast cancer patients. Cancer Epidemiol Biomarkers Prev 2005, 14: 1003-1007.

22. Tuttle TM, Habermann EB, Grund EH, Morris TJ, Virnig BA: Increasing use of contralateral prophylactic mastectomy for breast cancer patients: a trend toward more aggressive surgical treatment. J Clin Oncol 2007, 25:5203-5209.

23. Katipamula R, Hoskin TL, Boughey JC, Degnim AC, Grant CS, Brandt KR, Loprinzi CL, Pruthi S, MP G: Trends in mastectomy rates at the Mayo Clinic Rochester: Effect of surgical year and preoperative MRI. J Clin Oncol 2008, 26:(Suppl):abstract 509.

24. Evans DG, Lalloo F, Hopwood P, Maurice A, Baildam A, Brain A, Barr L, Howell A: Surgical decisions made by 158 women with hereditary breast cancer aged $<50$ years. Eur J Surg Oncol 2005, 31:1112-1118

25. Meijers-Heijboer H, Brekelmans CT, Menke-Pluymers M, Seynaeve $C$, Baalbergen $A$, Burger $C$, Crepin $E$, van den Ouweland AW, van Geel B, Klijn JG: Use of genetic testing and prophylactic mastectomy and oophorectomy in women with breast or ovarian cancer from families with a BRCA1 or BRCA2 mutation. J Clin Oncol 2003, 21:1675-1681.

26. Schwartz M, Lerman C, Brogan B, Peshkin B, Hughes Halbert C, DeMarco T, Lawrence W, Main D, Finch C, Magnant C, Pennanen $\mathrm{M}$, Tsangaris T, Willey S, Isaacs C: Impact of BRCA1/2 counseling and testing on newly diagnosed breast cancer patients. J Clin Oncol 2004, 22:1823-1829.

27. Easton DF, Ford D, Bishop DT, and the Breast Cancer Linkage Consortium: Breast and ovarian cancer incidence in BRCA1mutation carriers. Am J Hum Genet 1995, 56:265-271.

28. Kauff ND, Satagopan JM, Robson ME, Scheuer L, Hensley M,
Hudis CA, Ellis NA, Boyd J, Borgen PI, Barakat RR, Norton L, Castiel M, Nafa K, Offit K, Kauff ND, Satagopan JM, Robson ME, Scheuer L, Hensley M, Hudis CA, Ellis NA, Boyd J, Borgen PI, Barakat RR, Norton L, Castiel M, Nafa K, Offit K: Risk-reducing salpingo-oophorectomy in women with a BRCA1 or BRCA2 mutation. N Engl J Med 2002, 346:1609-1615.

29. Rebbeck TR, Lynch HT, Neuhausen SL, Narod SA, Van't Veer L, Garber JE, Evans G, Isaacs C, Daly MB, Matloff E, Olopade OI, Weber BL, For the Prevention and Observation of Surgical End Points Study Group: Prophylactic oophorectomy in carriers of BRCA1 or BRCA2 mutations. N Engl J Med 2002, 346:16161622.

30. Rebbeck TR, Levin AM, Eisen A, Snyder C, Watson P, CannonAlbright L: Breast cancer risk after prophylactic oophorectomy in BRCA1 mutation carriers. J Natl Cancer / 1999, 91:14751479.

31. Eisen A, Lubinski J, Klijn J, Moller P, Lynch HT, Offit K, Weber B, Rebbeck T, Neuhausen SL, Ghadirian P, Foulkes WD, GershoniBaruch R, Friedman E, Rennert G, Wagner T, Isaacs C, Kim-Sing $C$, Ainsworth P, Sun $P$, Narod SA: Breast cancer risk following bilateral oophorectomy in BRCA1 and BRCA2 mutation carriers: an international case-control study. J Clin Oncol 2005, 23: 7491-7496.

32. Howell A, Cuzick J, Baum M, Buzdar A, Dowsett M, Forbes JF, Hoctin-Boes G, Houghton J, Locker GY, Tobias JS, Group AT: Results of the ATAC (Arimidex, Tamoxifen, Alone or in Combination) trial after completion of 5 years' adjuvant treatment for breast cancer [see comment]. Lancet 2005, 365:60-62.

33. The Breast International Group (BIG) 1-98 Collaborative Group: A comparison of letrozole and tamoxifen in postmenopausal women with early breast cancer. N Engl J Med 2005, 353: 2747-2757.

34. Quinn JE, James CR, Stewart GE, Mulligan JM, White P, Chang GK, Mullan PB, Johnston PG, Wilson RH, Harkin DP, Quinn JE: BRCA1 mRNA expression levels predict for overall survival in ovarian cancer after chemotherapy [see comment]. Clin Canc Res 2007, 13:7413-7420.

35. Rottenberg $\mathrm{S}$, Nygren $\mathrm{AO}$, Pajic $\mathrm{M}$, van Leeuwen $\mathrm{FW}$, van der Heijden I, van de Wetering K, Liu X, de Visser KE, Gilhuijs KG, van Tellingen $O$, Schouten JP, Jonkers J, Borst P: Selective induction of chemotherapy resistance of mammary tumors in a conditional mouse model for hereditary breast cancer. Proc Natl Acad Sci USA 2007, 104:12117-12122.

36. Moller P, Evans D, Reis M, Gregory H, Anderson E, Maehle L, F L, Howell A, J A, Clark N, Lucassen A, Steel C: Surveillance for familial breast cancer: Differences in outcome according to BRCA mutation status. Int J Cancer 2007, 121:1017-1020.

37. Rakha E, El-Sheikh SE, Kandil MA, El-Sayed ME, Green AR, Ellis I: Expression of BRCA1 protein in breast cancer and its prognostic significance. Hum Patho/ 2008, 39:857-865.

38. De Soto J, Deng C: PARP-inhibitors: Are they the long-sought genetically specific drugs for BRCA1/2 associated breast cancers? Int J Med Sci 2006, 3:117-123.

39. Farmer H, McCabe N, Lord C, Tutt A, Johnson D, Richardson T, Santarosa M, Dillon K, Hickson I, Knights C, Martin N, Jackson S, Smith G, Ashworth A: Targeting the DNA repair defect in BRCA mutant cells as a therapeutic strategy. Nature 2005, 434:917920.

40. ClinicalTrials.gov [www.clinicaltrials.gov]

41. Fong P, Boss DS, Carden CP, Roelvink M, de Greve J, Gourley C, Carmichael J, de Bono JS, Schellens JH, Kaye SB: AZD2281 (KU-0059436), a PARP (poly ADP-ribose polymerase) inhibitor with single agent anticancer activity in patients with $B R C A$ deficient ovarian cancer: Results from a phase I study [abstract]. J Clin Oncol 2008, 26:5510.

42. Fackenthal J, Olopade O: Breast cancer risk associated with BRCA1 and BRCA2 in diverse populations. Nat Rev Cancer 2007, 7:937-948.

43. Loman $N$, Johannsson $O$, Kristoffersson $U$, Olsson $H$, Borg $A$ : Family history of breast and ovarian cancers and BRCA1 and $B R C A 2$ mutations in a population-based series of early-onset cancer. J Nat Cancer Inst 2001, 93:1215-1223.

44. Malone K, Daling J, Neal C, Suter N, O'Brien C, Cushing-Haugen $\mathrm{K}$, Jonasdottir T, Thompson J, Ostra E: Frequency of BRCA1/ BRCA2 mutations in a population-based sample of young breast carcinoma cases. Cancer 2000, 88:1393-1402.

45. National Breast Cancer Centre: Current Best Advice About 
Familial Aspects of Breast/ovarian Cancer. Sydney: NHMRC National Breast Cancer Centre; 2000.

46. McIntosh A, Shaw C, Evans G, Turnbull N, Bahar N, Barclay M, Easton D, Emery J, Gray J, Halpin J, Hopwood P, McKay J, Sheppard C, Sibbering M, Watson M, Wailoo A, Hutchinson A: Clinical Guidelines Evidence Review for The Classification Care of Women at Risk of Familial Breast Cancer. London: National Collaborating Centre for Primary Care, University of Sheffield; 2004.

47. Lalloo F, Varley J, Ellis D, Moran A, O'Dair L, Pharaoh P, Evans D, and the Early Onset Breast Cancer Group: Prediction of pathogenic mutations in patients with early-onset breast cancer by family history. Lancet 2003, 361:1101.

48. Choi D, Lee M, Bale A, Carter D, Haffty B: Incidence of BRCA1 and $B R C A 2$ mutations in young Korean breast cancer patients. J Clin Oncol 2004, 22:1638-1645.

49. Moller P, Hagen A, Apold J, Maehle L, Clark N, Fiane B, Lovslett K, Hovig E, Vabo A: Genetic epidemiology of BRCA mutations family history detects less than $50 \%$ of the mutation carriers. Eur J Cancer 2007, 43:1713-1717.

50. Herhardus A, Schleberger H, Schlegelberger B, Gadzicki D: Diagnostic accuracy of methods for the detection of BRCA1 and RBC2 mutations: A systematic review. Eur J Cancer 2007, 15:619-627.

51. Hopper JL, Southey MC, Dite GS, Jolley DJ, Giles GG, McCredie $M R$, Easton DF, Venter DJ: Population-based estimate of the average age-specific cumulative risk of breast cancer for a defined set of protein-truncating mutations in BRCA1 and BRCA2. Australian Breast Cancer Family Study. Cancer Epidemiol Biomarkers Prev 1999, 8:741-747.

52. Loizidou M, Marcou Y, Anastasiadou V, Newbold R, Hadjisavvas A, Kyriacou K: Contribution of BRCA1 and BRCA2 germline mutations to the incidence of early-onset breast cancer in Cyprus. Clin Genet 2007, 71:165-170.

53. Martínez-Ferrandis J, Vega A, Chirivella I, Marín-García $P$, Insa A, Lluch A, Carracedo A, Chaves F, García-Conde J, Cervantes A, Armengod M: Mutational analysis of BRCA1 and BRCA2 in Mediterranean Spanish women with early-onset breast cancer: Identification of three novel pathogenic mutations. Hum Mutat 2003, 22:417-418.

54. Lakhani SR, Van De Vijver MJ, Jacquemier J, Anderson TJ, Osin PP, McGuffog L, Easton DF: The pathology of familial breast cancer: predictive value of immunohistochemical markers estrogen receptor, progesterone receptor, HER-2, and p53 in patients with mutations in BRCA1 and BRCA2 [see comment]. $J$ Clin Oncol 2002, 20:2310-2318.

55. Atchley D, Albarracin C, Lopez A, Valero V, Amos C, GonzalezAngulo A, Hortobagyi G, Arun B: Clinical and pathological characteristics of patients with $B R C A$-positive and $B R C A$-negative breast cancer. J Clin Oncol 2008, 26:4282-4288.

56. Abeliovich D, Kaduri L, Lerer I, Weinberg N, Amir G, Sagi M, Zlotogora J, Heching N, Peretz T: The founder mutations 185delAG and 5382ins C in BRCA1 and 6174delT in BRCA2 appear in $60 \%$ of ovarian cancer and $30 \%$ of early-onset breast cancer patients among Ashkenazi women. Am J Hum Genet 1997, 60:505-514.

57. BRCA Risk Calculator and Mutation Prevalence Tables [http:// www.myriadtests.com/provider/brca-mutation-prevalence.htm]

58. Stolier AJ, Fuhrman GM, Mauterer L, Bolton JS, Superneau DW: Initial experience with surgical treatment planning in the newly diagnosed breast cancer patient at high risk for $B R C A$ 1 or BRCA-2 mutation [see comment]. Breast J 2004, 10:475480.

59. Warlam-Rodenhuis CC, Koot VC, van der Luijt RB, Vasen HF, Ausems MG: A prospective study on predictive factors linked to the presence of $B R C A 1$ and BRCA2 mutations in breast cancer patients. Eur J Cancer 2005, 41:1409-1415.

60. Schlich-Bakker KJ, Warlam-Rodenhuis CC, van Echtelt J, van den Bout J, Ausems MG, ten Kroode HF: Short term psychological distress in patients actively approached for genetic counselling after diagnosis of breast cancer. Eur J Cancer 2006, 42:2722-2728.

61. Meiser B: Psychological impact of genetic testing for cancer susceptibility: An update of the literature. Psychooncology 2005, 14:1060-1074.

62. Reichelt JG, Heimdal $\mathrm{K}$, Moller $\mathrm{P}, \mathrm{Dahl} \mathrm{AA}$ : BRCA1 testing with definitive results: A prospective study of psychological distress in a large clinic-based sample. Fam Cancer 2004, 3:21.
28

63. Loader S, Shields CG, Rowley PT: Impact of genetic testing for breast-ovarian cancer susceptibility. Genet Test 2004, 8:1-12.

64. van Roosmalen MS, Stalmeier PF, Verhoef LC, Hoekstra-Weebers JE, Oosterwijk JC, Hoogerbrugge N, Moog U, van Daal WA, van Roosmalen MS, Stalmeier PFM, Verhoef LCG, Hoekstra-Weebers JEHM, Oosterwijk JC, Hoogerbrugge N, Moog U, van Daal WAJ: Impact of $B R C A 1 / 2$ testing and disclosure of a positive test result on women affected and unaffected with breast or ovarian cancer. Am J Med Genet A 2004, 124:346-355.

65. Bonadona $V$, Saltel $P$, Desseigne $F$, Mignotte $H$, Saurin JC, Wang Q, Sinilnikova O, Giraud S, Freyer G, Plauchu H, Puisieux A, Lasset C, Bonadona V, Saltel P, Desseigne F, Mignotte H, Saurin J-C, Wang O, Sinilnikova O, Giraud S, Freyer G, Plauchu H, Puisieux A, Lasset C: Cancer patients who experienced diagnostic genetic testing for cancer susceptibility: reactions and behavior after the disclosure of a positive test result. Cancer Epidemiol Biomarkers Prev 2002, 11:97-104.

66. Graves K, Peshkin B, Halbert C, DeMarco T, Isaacs C, Schwartz $\mathrm{M}$ : Predictors and outcomes of contralateral prophylactic mastectomy among breast cancer survivors. Breast Cancer Res $\operatorname{Tr}$ 2007, 104:321-329.

67. Tercyak KP, Peshkin BN, Brogan BM, DeMarco T, Pennanen MF, Willey SC, Magnant CM, Rogers S, Isaacs C, Schwartz MD: Quality of life after contralateral prophylactic mastectomy in newly diagnosed high-risk breast cancer patients who underwent BRCA1/2 gene testing. J Clin Oncol 2007, 25:285-291.

68. Metcalfe KA, Lubinski J, Ghadirian $\mathrm{P}$, Lynch H, Kim-Sing C, Friedman E, Foulkes WD, Domchek S, Ainsworth P, Isaacs C, Tung N, Gronwald J, Cummings S, Wagner T, Manoukian S, Moller P, Weitzel J, Sun P, Narod SA, Hereditary Breast Cancer Clinical Study G: Predictors of contralateral prophylactic mastectomy in women with a BRCA1 or BRCA2 mutation: the Hereditary Breast Cancer Clinical Study Group. J Clin Oncol 2008, 26: 1093-1097.

69. Daly MB: Tailoring breast cancer treatment to genetic status: the challenges ahead [comment]. J Clin Oncol 2004, 22:17761777.

70. Schlich-Bakker $\mathrm{K}$, Ausems ME, Schipper M, Ten Kroode $\mathrm{H}$ Warlam-Rodenhuis C, Van den Bout J: BRCA1/2 mutation testing in breast cancer patients: a prospective study of the long-term psychological impact of approach during adjuvant radiotherapy. Breast Cancer Res Treat 2008, 109:507-514.

71. Schlich-Bakker K, Ten Kroode H, Warlam-Rodenhuis C, Van den Bout J, Ausems M: Barriers to participating in genetic counselling and $B R C A$ testing during primary treatment for breast cancer. Breast Cancer Res Treat 2007, 11:766-777.

72. Ardern-Jones A, Kenen R, Eeles R: Too much too soon? Patients' and health professionals' views concerning the impact of genetic testing at the time of breast cancer diagnosis in women under the age of 40. Eur J Cancer Care 2005, 14: 272-281.

73. Lobb E, Hallowell N, Barlow-Stewart K, Suthers G: Determining the genetic status of women newly diagnosed with breast cancer prior to treatment decision: An ethical challenge. Eur J Hum Genet 2008, 16(Suppl 2):437.

74. O'Connor A, Stacey D, Rovner D, Holmes-Rovner M, Tetroe J, Llewellyn-Thomas $\mathrm{H}$, Entwistle V, Rostom A, Fiset V, Barry M, Jones J: Decision aids for people facing health treatment or screening decisions. Cochrane Database Syst Rev 2001:CD001431

75. Lobb EA, Butow PN, Moore A, Barratt A, Tucker K, Gaff C, Kirk J, Dudding T, Butt D: Development of a communication aid to facilitate risk communication in consultations with unaffected women from high risk breast cancer families: a pilot study. $J$ Genet Counseling 2006, 15:393-405.

76. Wakefield C, Meiser B, Homewood J, Taylor A, Gleeson M, Williams R, Tucker K, and the AGenDA Collaborative Group: A randomized trial of a breast/ovarian cancer genetic testing decision aid used as a communication aid during genetic counseling. Psychooncology 2008, 17:844-854.

77. Wakefield C, Meiser B, Homewood J, Peate M, Taylor A, Lobb E, Kirk J, Young M, Williams R, Dudding T, Tucker K, and the AGenDA Collaborative Group: A randomized controlled trial of a decision aid for women considering genetic testing for breast and ovarian cancer risk Breast Cancer Res Treat 2008, 107:289-301. 
78. Uhrhammer N, Abdelouahab A, Lafarge L, Feillel V, Dib A, Bignon $\mathrm{Y}$ : BRCA1 mutations in Algerian breast cancer patients: High frequency in young, sporadic cases. Int J Med Sci 2008, 5:197202.

79. Haffty B, Silber A, Matloff E, Chung J, Lannin D: Racial differences in the incidence of BRCA1 and BRCA2 mutations in a cohort of early onset breast cancer patients: African American compared to white women. J Med Genet 2006, 43:133-137.

80. Hamann U, Liu X, Bungardt N, Ulmer HU, Bastert G, Sinn H-P: Similar contributions of BRCA1 and BRCA2 germline mutations to early-onset breast cancer in Germany. Eur J Hum Genet 2003, 11:464-467.

81. Bonadona V, Sinilnikova OM, Chopin S, Antoniou AC, Mignotte $H$, Mathevet $P$, Brémond $A$, Martin A, Bobin JY, Romestaing $P$, Raudrant D, Rudigoz RC, Léoné M, Chauvin F, Easton DF, Lenoir GM, Lasset C: Contribution of BRCA1 and BRCA2 germ-line mutations to the incidence of breast cancer in young women: Results from a prospective population-based study in France. Genes Chromosomes Cancer 2005, 43:404-413

82. de Sanjose S, Leone M, Berez V, Izquierdo A, Font R, Brunet J, Louat T, Vilardell L, Borras J, Viladiu P, Bosch F, Lenoir G, Sinilnikova O: Prevalence of BRCA1 and BRCA2 germline mutations in young breast cancer patients: a population-based study. Intern J Canc 2003, 106:588-593.

83. Malone KE, Daling JR, Thompson JD, O'Brien CA, Francisco LV, Ostrander EA: BRCA1 mutations and breast cancer in the general population: Analyses in women before age 35 years and in women before age $\mathbf{4 5}$ years with first-degree family history [see comment]. JAMA 1998, 279:922-929.

84. Plaschke J, Commer T, Jacobi C, Schackert HK, Chang-Claude J: BRCA2 germline mutations among early onset breast cancer patients unselected for family history of the disease. $J$ Med Genet 2000, 37:E17.

85. Ho GH, Phang $\mathrm{BH}, \mathrm{Ng}$ IS, Law HY, Soo KC, Ng EH: Novel germline BRCA1 mutations detected in women in singapore who developed breast carcinoma before the age of $\mathbf{3 6}$ years. Cancer 2000, 89:811-816.

86. Yassaee V, Zeinali S, Harirchi I, Jarvandi J, Mohagheghi M, Hornby $\mathrm{D}$, Dalton A: Novel mutations in the BRCA1 and BRCA2 genes in Iranian women with early-onset breast cancer. Breast Cancer Res 2002, 4:R6.

87. Anglican Breast Cancer Study Group: Prevalence and penetrance of BRCA1 and BRCA2 mutations in a population-based series of breast cancer cases. Anglican Breast Cancer Study Group. Br J Cancer 2000, 83:1301-1308.

88. Southey M, Tesoriero A, Andersen C, Jennings K, Brown S, Dite G, Jenkins M, Osborne R, Maskiell J, Porter L, Giles G, McCredie M, Hopper J, Vent D: BRCA1 mutations and other sequence variants in a population-based sample of Australian women with breast cancer. $\mathrm{Br} J$ Cancer 1999, 79:34-39.

89. Krainer M, Silva-Arrieta S, FitzGerald MG, Shimada A, Ishioka C, Kanamaru R, MacDonald DJ, Unsal H, Finkelstein DM, Bowcock A, Isselbacher $\mathrm{KJ}$, Haber DA: Differential contributions of $B R C A 1$ and BRCA2 to early-onset breast cancer [see comment]. N Engl J Med 1997, 336:1416-1421.

90. Peto J, Collins N, Barfoot R, Seal S, Warren W, Rahman N, Easton DF, Evans C, Deacon J, Stratton MR: Prevalence of BRCA1 and BRCA2 gene mutations in patients with earlyonset breast cancer [see comment]. J Nat/ Cancer / 1999, 91: 943-949.

91. Lubinski J, Gorski B, Huzarski T, Byrski T, Gronwald J, J S-Fn, Domaga $^{3}$ a W, Chosia M, Ucinski M, Grzybowska E, Lange D, Maka B, Mackiewicz A, Karczewska A, Breborowicz J, Lamperska K, Stawicka M, Gozdecka-Grodecka S, Bebenek M, Sorokin D, Wojnar A, Haus O, Sir J, Mierzwa T, Niepsuj S, Guga ${ }^{3} a$ K, Gozdz $\mathrm{S}$, Sygut J, Kozak-Klonowska B, Musiatowicz B, et al:: BRCA1positive breast cancers in young women from Poland. Breast Cancer Res Treat 2006, 99:71-76.

92. Robson M, Gilewski T, Haas B, Levin D, Borgen P, Rajan R, Hirschaut Y, Pressman P, Rosen P, Lesser M, Norton L, Offit K: $B R C A$-associated breast cancer in young women. J Clin Oncol 1998, 16:1642-1649.

93. Gershoni-Baruch R, Dagan E, Fried G, Bruchim Bar-Sade R, Sverdlov-Shiri R, Zelicksson G, Friedman E: Significantly lower rates of $B R C A 1 / B R C A 2$ founder mutations in Ashkenazi women with sporadic compared with familial early onset breast cancer. Eur J Cancer 2000, 36:983-986.
94. Tonin P, Perret C, Lambert J, Paradis A, Kantemiroff T, Benoît M, Martin G, Foulkes W, Ghadirian P: Founder BRCA1 and BRCA2 mutations in early-onset French Canadian breast cancer cases unselected for family history. Intern J Canc 2001, 20: 189-193.

95. Lalloo F, Varley J, Moran A, Ellis D, O'Dair L, Pharaoh P, Antoniou A, Hartley R, Shenton A, Seal S, Bulman B, Howell A, Evans D: $B R C A 1, B R C A 2$ and T53 mutations in very early-onset breast cancer with asociated risks for relatives. Eur J Cancer 2006 , 42:1143-1150.

96. National Breast Cancer Centre: Advice About Familial Aspects of Breast Cancer and Epithelial Ovarian Cancer: A Guide for Health Professionals. Sydney: NHMRC National Breast Cancer Centre; 2006. 